\title{
Gender Differences in Dynamic of Family Stress Indicators in Population Aged 25-64 Years from 1988 To 2017
}

\author{
Gafarov VV ${ }^{* 1,2}$, Elena Gromova ${ }^{1,2}$, Dmitriy Panov ${ }^{1,2}$, Gagulin IV ${ }^{1,2}$ and Gafarova AV AV $^{1,2}$ \\ ${ }^{1}$ Institute of Internal and Preventive Medicine - branch of \\ ${ }^{*}$ Corresponding authors \\ Institute of Cytology and Genetics RAS, Novosibirsk; \\ Valery V Gafarov, Institute of Internal and Preventive Medicine - branch \\ ${ }^{2}$ Collaborative laboratory of Cardiovascular Diseases \\ of Institute of Cytology and Genetics RAS, Collaborative laboratory of \\ Cardiovascular Diseases Epidemiology, Novosibirsk
}

Epidemiology, Novosibirsk

Submitted: 19 March 2021;Accepted:25 March 2021;Published: 05 Apr 2021

Citation: Gafarov VV, Panov DO, Gromova EA, Krymov EA, Gagulin IV, et al. (2021) Gender Differences in Dynamic of Family Stress Indicators in Population Aged 25-64 Years from 1988 To 2017. Medical \& Clinical Research 6(4): 520-526.

\begin{abstract}
The aim: To determine gender differences in the dynamic of family stress indicators in an open population of 25-64 years over a long-term period - 29 years in Russia / Siberia (Novosibirsk).

Methods: Within the framework of the screening in 1988-89 under the WHO MONICA-psychosocial program ( $n=1676$, $49.5 \%$ males, mean age 44.1 \pm 0.4 years), in 2003-2005 under the international project HAPIEE ( $n=1650,34.9 \%$ males, mean age 54.25 \pm 0.2 years), in 2013-2016 ( $n=975$, 43.8\% males, mean age 34.5 $\pm 0,4$ years) and 2016-2017 ( $n=663,41.3 \%$ years $51.95 \pm 0.32$ years) within the framework of the budgetary theme No. AAAA-A17-117112850280-2, random representative samples of men and women in one of districts in Novosibirsk were examined. Family stress indicators were assessed using the questionnaire "Knowledge and attitude towards own's health".

Results: In 1988, men were 7\% more likely than women to report serious illness or death of close relatives in the past year. By 2016-17, the share of such persons decreased to 20.1\% of men and 28.1\% of women. Women more often than men reported changes in marital status over the past 12 months in 1988: married, divorced, left family, widowed, had a child, etc. The frequency of these changes was higher in the younger age group. In 2013-2015, these changes occurred equally often in men and women but their share decreased subsequently. The difference in the perception of conflicts in the family is present among men and women aged 25-64. In 1988, men more often than women believed that there were no serious conflicts in the family, especially in the younger age groups. Gender gap towards family conflicts is reducing among older participants. The proportion of women who reported family conflicts dropped significantly in 2013-2016 and 2016-17. It has led to gender parity in the frequency of family disagreements. Men more often than women reported that "something disturbs their rest at dwelling ". By 2017, the proportion of such persons increased, reaching the maximum levels (80-90\%) among men and women in certain age groups.
\end{abstract}

Conclusions: Women are more likely than men to report changes in marital status and conflicts in the family. Men are more often than women dissatisfied with rest at home. Gender differences are diminished with age.

Keywords: Family Stress, Gender, Trends

\section{Introduction}

Up to $40 \%$ of people who have suffered the death of close relatives (spouse or child) subsequently experience post-traumatic disorder. Women are more likely than men to report anxiety and severe distress in response to memories of psychological trauma. Men who have experienced such stress more often than women indicate the presence of a feeling of detachment / detachment from others [1]. However, it remains unclear whether the distribution of these two types of response is related to gender as a biological factor or/ and a social role or a combination of both $[1,2]$. The perception of family stress is unequal. The male sex reacts more sharply to the loss of close friends but for women it concerned family members and children. "Family balance" determines the type of emotional response to psychological difficulties, taking into account gender roles. Feelings of guilt and helplessness are more often associated with depression in women than in men as an emotional response to family stress. A long-term persistent exposure to home stress is associated with the subsequent anxiety and the development of other psychological complications [1].

Med Clin Res, $2021 \quad$ www.medclinres.org

Volume 6 | Issue 4 | 520 
Changes in marital status (divorce, death of a spouse) are especially reflected in mental health not only due to financial difficulties but due to the lack of social support and the presence of stress factors in the family and conflict between work and family [3]. Such an internal conflict "family-work" is associated with the burden of housekeeping. It is known that $27.3 \%$ of women and only $1.2 \%$ of men report the need to be at home and at work the same time [4]. Geographical and cultural traditions indicate gender differences in family responsibilities in household chores [5]: for example, $69.5 \%$ of men never clean toilets and $35 \%$ do not know how to do it. On the other hand, the conflict "family-career" takes on a higher significance in single-parent families given the lower wages in the labor market for women compared to men. This is probably related to the higher frequency of reported family problems $(17.9 \%$ and $28.5 \%$ for men and women) and high financial stress $(25.4 \%$ and $28.5 \%$, respectively) among women [3].

Our research complements these prior scientific reports. Evaluating a large number of people from the general population participating in screening over the years but with a common design, increases the generalizability and relevance required for epidemiological protocols based on research principles. Thus, the aim of our study was to explore gender differences in the dynamics of family stress indicators in population aged of 25-64 years over a long-term period - 29 years.

\section{Methods}

The results of our study were obtained on the basis of a survey of the male and female population living in one of the districts of Novosibirsk. The examinations were carried out within the framework of screenings 1988-89, 2003-2005, 2013-2016 and 2016-2017.

Under the II screening of the WHO program «Multinational Monitoring of Trends and Determinants of Cardiovascular Disease - Optional Psychosocial Sybstudy» (MONICA-MOPSY) representative sample of residents aged 25-64 years was examined in 1988-1989 $(\mathrm{n}=1676,49.5 \%$ males, mean age $44.1 \pm 0.4$ years, response rate $-69.8 \%)$ [6].

In the course of another international project HAPIEE (Health, Alcohol and Psychosocial Factors in Eastern Europe) persons aged 45-64 were examined in 2003-2005 $(n=1650,34.9 \%$ males, mean age $54.25 \pm 0.2$ years, response rate $-66.5 \%$ ) [7].

In the framework of the screening studies a random representative sample survey of the population aged 25-44 years conducted in 2013-2016 by the budget scientific research theme, Gov. Task № $01201282292(n=975,43.8 \%$ males, mean age $34.5 \pm 0.4$ years, response rate $-71.5 \%)$.

Within the framework of the budget theme No. AAAA-A17-117112850280-2 a survey of persons aged 35-64 was carried out in 2016-2017 $(n=663,41.3 \%$ males, mean age $51.95 \pm 0.32$ years, response rate $-73.6 \%)$. The study included residents of the same district of Novosibirsk as in 1994-95, 20032005 and 2013-2016.

All samples were formed on the basis of electoral lists of citizens using a table of random numbers. A random mechanical selection procedure was used. The general survey was carried out according to the standard methods accepted in epidemiology and included in the MONICA program [6, 7]. The methods were strictly standardized and complied with the requirements of the MONICA project protocol. Validation and processing of material according to the WHO MONICA-psychosocial program was carried out at the Information Collection Center of the MEDIS Institute in Munich, Germany (Institut für Medizinische Informatik und Systemforschung). Quality control was carried out in MONICA quality control centers: Dundee (Scotland), Prague (Czech Republic), Budapest (Hungary). The presented results were considered satisfactory.

The screening survey program included registration of sociodemographic data according to the standard epidemiological protocol of the WHO MONICA-psychosocial program: identification number, place of residence, full name, date of birth, date of registration, gender, marital status, educational level, professional status.

Indicators of family stress were studied using the "Knowledge and Attitude to Own's Health" scale proposed by the MOPSY protocol and adapted to the studied population [8]. The subjects were asked to answer the questions of the scale themselves according to the instructions placed on the scale. Individuals who did not complete the questionnaire were not included in the analysis.

Statistical analysis was performed using the SPSS software package version 11.5. The study participants were standardized by age groups in the analysis. To compare the indicators between screenings, the corresponding age groups were used. To check the statistical significance of differences between groups, we used: the chi-square test $(\chi 2)$. As a criterion of statistical significance the value of the chi-square was taken into account at a certain number of degrees of freedom. The reliability of analysis was accepted at a significance level of $\mathrm{p}<0.05$.

\section{Results}

In 1988 , men were $7 \%$ more likely than women to report serious illness or death of close relatives over the past year: $72.8 \%$ and $65.4 \%(\mathrm{p}<0.01)$. This proportion was identical across the age groups. In 2003-05, the share of those who experienced the loss or serious illness of close relatives significantly decreased among persons of both sexes to $30-40 \%$. At the same time, men began to report such events less often than women, especially in the middle age group $45-54$ years: $31.2 \%$ and $40.3 \%$, respectively (p $<0.05$ ). In the younger age groups in 2013-16, the frequency of reports of illness or death of relatives decreased by 3-3.5 times in comparison with 1988, reaching equal values - $20 \%$ in the group of 25-34 years (n.s.). The share of those who reported such emotionally adverse events by 2016-17 decreased stronger in those aged $35-44$ years: $12.7 \%$ of men and $21.4 \%$ of women. The proportion of such participants increased in older age groups but was significantly lower than in $1988: 20.1 \%$ of men and $28.1 \%$ of women $(p<0.05)$.

In 1988, women aged of 25-64 years more often than men reported changes in marital standing over the past 12 months: married, 
divorced, left the family, widowed, had a child, other $(14.1 \%$ of men and $19.2 \%$ of women; $p<0,05)$. The frequency of these changes was higher in the younger age group. The proportion of women reported several life events in their family over the past year was higher reaching $6.7 \%$ in this group versus $4.5 \%$ in men (n.s.). In 2003-05, the number of reports concerning changes in marital status increased among women, especially in those aged 45-54 years - up to $25.5 \%$; however, the frequency of events in men remained at the same level. It was increased the gender gap $(\mathrm{p}<0.001)$. In 2013-2015, changes in marital standing occurred equally often in men and women, increasing in the group of 25 34 years up to $28 \%$ (the sum of the answers "one change" and "several changes"). In those aged of 35-44 years the frequency of such changes was at the 1988 level.

In 2016-17, the number of respondents with changes in marital standing during the year decreased significantly. In the group of men aged of 35-44 years this share was $2.8 \%$, and for women it did not exceed $10 \%$ in all age groups.

Table 1: Gender differences in trends of family stress indicators in population of 25-64 years depending on age

\begin{tabular}{|c|c|c|c|c|c|c|c|c|c|c|c|c|c|c|c|c|c|c|c|c|c|}
\hline & & \multicolumn{4}{|c|}{ 25-34 years } & \multicolumn{4}{|c|}{ 35-44 years } & \multicolumn{4}{|c|}{ 45-54 years } & \multicolumn{4}{|c|}{ 55-64 years } & \multicolumn{4}{|c|}{ 25-64 years } \\
\hline & & \multicolumn{2}{|c|}{ M } & \multicolumn{2}{|l|}{$\mathbf{F}$} & \multicolumn{2}{|l|}{$\mathbf{M}$} & \multicolumn{2}{|l|}{$\mathbf{F}$} & \multicolumn{2}{|l|}{$\mathbf{M}$} & \multicolumn{2}{|l|}{$\mathbf{F}$} & \multicolumn{2}{|l|}{ M } & \multicolumn{2}{|l|}{$\mathbf{F}$} & \multicolumn{2}{|l|}{ M } & \multicolumn{2}{|l|}{$\mathbf{F}$} \\
\hline & & $\mathbf{N}$ & $\%$ & $\mathbf{N}$ & $\%$ & $\mathbf{N}$ & $\%$ & $\mathbf{N}$ & $\%$ & $\mathbf{N}$ & $\%$ & $\mathbf{N}$ & $\%$ & $\mathbf{N}$ & $\%$ & $\mathbf{N}$ & $\%$ & $\mathbf{N}$ & $\%$ & $\mathbf{N}$ & $\%$ \\
\hline \multicolumn{22}{|c|}{ Has anyone close to you been seriously ill or died within 12 months? } \\
\hline Yes & \multirow[t]{4}{*}{1988} & 151 & 74 & 119 & 65.7 & 146 & 73.7 & 138 & 66.3 & 119 & 70 & 116 & 64.1 & 110 & 73.3 & 87 & 66.9 & 530 & 72.8 & 464 & 65.4 \\
\hline No & & 53 & 26 & 62 & 34.3 & 52 & 26.3 & 70 & 33.7 & 51 & 30 & 65 & 35.9 & 40 & 26.7 & 43 & 33.1 & 198 & 27.2 & 245 & 34.6 \\
\hline Total & & 204 & 100 & 181 & 100 & 198 & 100 & 208 & 100 & 170 & 100 & 181 & 100 & 150 & 100 & 130 & 100 & 728 & 100 & 709 & 100 \\
\hline & & \multicolumn{4}{|c|}{$\chi^{2}=2.752 \mathrm{df}=1 \mathrm{p}=0.097$} & \multicolumn{4}{|l|}{ n.s. } & \multicolumn{4}{|l|}{ n.s. } & \multicolumn{4}{|l|}{ n.s. } & \multicolumn{4}{|c|}{$\chi^{2}=8.777 \mathrm{df}=1 \mathrm{p}<0.01$} \\
\hline Yes & \multirow[t]{4}{*}{2003} & & & & & & & & & 95 & 31.2 & 223 & 40.3 & 98 & 36 & 207 & 39.8 & 193 & 33.5 & 430 & 40 \\
\hline No & & & & & & & & & & 209 & 68.8 & 331 & 59.7 & 174 & 64 & 313 & 60.2 & 383 & 66.5 & 644 & 60 \\
\hline \multirow[t]{2}{*}{ Total } & & & & & & & & & & 304 & 100 & 554 & 100 & 272 & 100 & 520 & 100 & 576 & 100 & 1074 & 100 \\
\hline & & & & & & & & & & \multicolumn{4}{|c|}{$\chi^{2}=6.440 \mathrm{df}=1 \mathrm{p}<0.05$} & \multicolumn{4}{|l|}{ n.s. } & \multicolumn{4}{|c|}{$\chi^{2}=6.528 \mathrm{df}=1 \mathrm{p}<0.05$} \\
\hline Yes & \multirow[t]{4}{*}{2013} & 34 & 20.6 & 46 & 21.6 & 52 & 19.8 & 95 & 28.4 & & & & & & & & & 86 & 20.1 & 141 & 25.7 \\
\hline No & & \begin{tabular}{|l|}
131 \\
\end{tabular} & 79.4 & 167 & \begin{tabular}{|l|}
78.4 \\
\end{tabular} & 210 & 80.2 & 240 & \begin{tabular}{|l|}
71.6 \\
\end{tabular} & & & & & & & & & 341 & \begin{tabular}{|l|}
79.9 \\
\end{tabular} & 407 & 74.3 \\
\hline Total & & 165 & 100 & 213 & 100 & 262 & 100 & 335 & 100 & & & & & & & & & 427 & 100 & 548 & 100 \\
\hline & & n.s. & & & & $\chi^{2}=5$. & $288 \mathrm{df}$ & $=1 \mathrm{p}<$ & 0.05 & & & & & & & & & $\chi^{2}=3$. & $891 \mathrm{df}$ & $=1 \mathrm{p}<0$ & \\
\hline Yes & 2017 & & & & & 9 & 12.7 & 21 & 21.4 & 14 & 17.1 & 34 & 24.6 & 32 & 26.4 & 53 & 35.8 & 55 & 20.1 & 108 & 28.1 \\
\hline No & & & & & & 62 & 87.3 & 77 & 78.6 & 68 & 82.9 & \begin{tabular}{|l|}
104 \\
\end{tabular} & \begin{tabular}{|l|}
75.4 \\
\end{tabular} & 89 & 73.6 & 95 & 64.2 & 219 & \begin{tabular}{|l|}
79.9 \\
\end{tabular} & 276 & 71.9 \\
\hline Total & & & & & & 71 & 100 & 98 & 100 & 82 & 100 & 138 & 100 & 121 & 100 & 148 & 100 & 274 & 100 & 384 & 100 \\
\hline & & & & & & n.s. & & & & n.s. & & & & n.s. & & & & $\chi^{2}=5$. & $139 \mathrm{df}$ & $=1 \mathrm{p}<0$ & \\
\hline
\end{tabular}


Table 2. Gender differences in trends of family stress indicators in population of 25-64 years depending on age

\begin{tabular}{|c|c|c|c|c|c|c|c|c|c|c|c|c|c|c|c|c|c|c|c|}
\hline \multicolumn{4}{|c|}{ 25-34 years } & \multicolumn{4}{|c|}{$35-44$ years } & \multicolumn{4}{|c|}{ 45-54 years } & \multicolumn{4}{|c|}{ 55-64 years } & \multicolumn{4}{|c|}{ 25-64 years } \\
\hline$\overline{\mathbf{M}}$ & & $\mathbf{F}$ & & $\mathbf{M}$ & & $\mathbf{F}$ & & $\mathbf{M}$ & & $\mathbf{F}$ & & $\overline{\mathbf{M}}$ & & $\mathbf{F}$ & & $\mathbf{M}$ & & $\mathbf{F}$ & \\
\hline $\mathbf{N}$ & $\%$ & $\mathbf{N}$ & $\%$ & $\mathbf{N}$ & $\%$ & $\mathbf{N}$ & $\%$ & $\mathbf{N}$ & $\%$ & $\mathbf{N}$ & $\%$ & $\mathbf{N}$ & $\%$ & $\mathbf{N}$ & $\%$ & $\mathbf{N}$ & $\%$ & $\mathbf{N}$ & $\%$ \\
\hline
\end{tabular}

Has your marital standing changed over the past 12 months: married, divorced, left the family, widowed, a child was born, another?

\begin{tabular}{|c|c|c|c|c|c|c|c|c|c|c|c|c|c|c|c|c|c|c|c|c|c|}
\hline $\begin{array}{l}\text { No } \\
\text { changes }\end{array}$ & \multirow[t]{5}{*}{1988} & 164 & 81.2 & 132 & 73.7 & 171 & 87.2 & 170 & 82.1 & 147 & 86.5 & 147 & 83.5 & 134 & 89.9 & 112 & 85.5 & 621 & 85.9 & 567 & 80.8 \\
\hline $\begin{array}{l}\text { One } \\
\text { change }\end{array}$ & & 29 & 14.4 & 35 & 19.6 & 20 & 10.2 & 25 & 12.1 & 17 & 10.0 & 23 & 13.1 & 10 & 6.7 & 13 & 9.9 & 77 & 10.6 & 97 & 13.8 \\
\hline $\begin{array}{l}\text { Several } \\
\text { changes }\end{array}$ & & 9 & 4.5 & 12 & 6.7 & 5 & 2.6 & 12 & 5.8 & 6 & 3.5 & 6 & 3.4 & 5 & 3.4 & 6 & 4.6 & 25 & 3.5 & 38 & 5.4 \\
\hline \multirow[t]{2}{*}{ Total } & & 202 & 100 & 179 & 100 & 196 & 100 & 207 & 100 & 170 & 100 & 176 & 100 & 149 & 100 & 131 & 100 & 723 & 100 & 702 & 100 \\
\hline & & \multicolumn{4}{|l|}{ n.s. } & \multicolumn{4}{|l|}{ n.s. } & \multicolumn{4}{|l|}{ n.s. } & \multicolumn{4}{|l|}{ n.s. } & \multicolumn{4}{|c|}{$\chi^{2}=7.128 \mathrm{df}=2 \mathrm{p}<0.05$} \\
\hline $\begin{array}{l}\text { No } \\
\text { changes }\end{array}$ & \multirow[t]{5}{*}{2003} & & & & & & & & & 263 & 86.5 & 413 & 74.5 & 227 & 83.5 & 416 & 80.0 & 490 & 85.1 & 829 & 77.2 \\
\hline $\begin{array}{l}\text { One } \\
\text { change }\end{array}$ & & & & & & & & & & 33 & 10.9 & 109 & 19.7 & 35 & 12.9 & 79 & 15.2 & 68 & 11.8 & 188 & 17.5 \\
\hline $\begin{array}{l}\text { Several } \\
\text { changes }\end{array}$ & & & & & & & & & & 8 & 2.6 & 32 & 5.8 & 10 & 3.7 & 25 & 4.8 & 18 & 3.1 & 57 & 5.3 \\
\hline \multirow[t]{2}{*}{ Total } & & & & & & & & & & 304 & 100 & 554 & 100 & 272 & 100 & 520 & 100 & 576 & 100 & 1074 & 100 \\
\hline & & & & & & & & & & \multicolumn{4}{|c|}{$\begin{array}{l}\chi^{2}=16.956 \mathrm{df}=2 \\
\mathrm{p}<0.001\end{array}$} & \multicolumn{4}{|l|}{ n.s. } & \multicolumn{4}{|c|}{$\chi^{2}=14.690 \mathrm{df}=2 \mathrm{p}<0.001$} \\
\hline $\begin{array}{l}\text { No } \\
\text { changes }\end{array}$ & \multirow[t]{5}{*}{2013} & 117 & 70.9 & 154 & 72.3 & 221 & 84.4 & 285 & 85.1 & & & & & & & & & 338 & 79.2 & 439 & 80.1 \\
\hline $\begin{array}{l}\text { One } \\
\text { change }\end{array}$ & & 39 & 23.6 & 50 & 23.5 & 33 & 12.6 & 43 & 12.8 & & & & & & & & & 72 & 16.9 & 93 & 17.0 \\
\hline $\begin{array}{l}\text { Several } \\
\text { changes }\end{array}$ & & 9 & 5.5 & 9 & 4.2 & 8 & 3.1 & 7 & 2.1 & & & & & & & & & 17 & 4.0 & 16 & 2.9 \\
\hline \multirow[t]{2}{*}{ Total } & & 165 & 100 & 213 & 100 & 262 & 100 & 335 & 100 & & & & & & & & & 427 & 100 & 548 & 100 \\
\hline & & \multicolumn{4}{|l|}{ n.s. } & \multicolumn{4}{|l|}{ n.s. } & & & & & & & & & \multicolumn{4}{|l|}{ n.s. } \\
\hline $\begin{array}{l}\text { No } \\
\text { changes }\end{array}$ & \multirow[t]{5}{*}{2017} & & & & & 69 & 97.2 & 89 & 90.8 & 72 & 87.8 & 124 & 89.9 & 107 & 88.4 & 138 & 90.2 & 248 & 90.5 & 351 & 90.2 \\
\hline $\begin{array}{l}\text { One } \\
\text { change }\end{array}$ & & & & & & 2 & 2.8 & 5 & 5.1 & 5 & 6.1 & 11 & 8.0 & 8 & 6.6 & 8 & 5.2 & 15 & 5.5 & 24 & 6.2 \\
\hline $\begin{array}{l}\text { Several } \\
\text { changes }\end{array}$ & & & & & & 0 & 0 & 4 & 4.1 & 5 & 6.1 & 3 & 2.2 & 6 & 5.0 & 7 & 4.6 & 11 & 4.0 & 14 & 3.6 \\
\hline \multirow[t]{2}{*}{ Total } & & & & & & 71 & 100 & 98 & 100 & 82 & 100 & 138 & 100 & 121 & 100 & 153 & 100 & 274 & 100 & 389 & 100 \\
\hline & & & & & & \multicolumn{4}{|c|}{ n.s. } & \multicolumn{4}{|l|}{ n.s. } & \multicolumn{4}{|l|}{ n.s. } & \multicolumn{4}{|l|}{ n.s. } \\
\hline
\end{tabular}

Men aged of 25-64 years more often than women believed that there were no serious conflicts in the family over the past 12 months: $71.2 \%$ and $58.8 \%$, respectively $(\mathrm{p}<0.001)$. This sex difference in the perception of such events was evident in the younger age groups and it was $15 \%$ between men and women $(\mathrm{p}<0.001)$. The presence of one or several serious conflicts was reported by an approximately equal proportion of men and women. But women of younger age in 3-3.5 times higher reported frequent conflicts in the family compared with men $(\mathrm{p}<0.001)$. Attitude toward such events was the same in older age groups in which gender differences was disappearing.

In 2003-2005, men and women were more likely to report at least one serious conflict compared to previous screening, especially in the oldest group of $55-64$ years: $26.5 \%$ and $30.4 \%$, respectively $(p=0.054)$. At the same time, women were $10 \%$ ahead of men in the frequency of reporting about any conflicts in the family.

The proportion of women who reported family conflicts dropped significantly in the younger age groups in 2013-2016. This 
decrease mainly affected those who reported frequent conflicts in the family: down to $2.3 \%$ in the groups of 25-34 and 35-44 years. But the proportion of persons with "one" or "several" serious family conflicts was still higher among women: $26.5 \%$ and $35.2 \%$ of men and women aged of 25-44 years $(\mathrm{p}<0.05)$.

In 2016-17, the proportion of women without serious conflicts in the family increased during the year. Conflicts decreased only in the oldest men aged of 55-64 years. These changes have led to gender parity in the frequency of family conflicts. Gender differences in 2016-17 persisted only in the 45-54 age group in which women 2.5 times were more likely to report "one serious conflict" during the year $(p<0.05)$. Otherwise, the structure of the responses was identical by gender.

In $1988,71 \%$ of men and $57 \%$ of women aged of $25-64$ years reported that "something interferes to have a rest at dwelling" ( $p$
$<0.001)$. The proportion of such men was $23 \%$ higher than women in the youngest age group 25-34 years $(\mathrm{p}<0.001)$. The proportion of people who cannot rest at dwelling increased with age, reaching $83.6 \%$ and $68.7 \%$ among men and women $55-64$ years $(p<0.01)$. In $2003-2005$, their share decreased to $75 \%$ of men and $63.7 \%$ of women in this age group $(p<0.01)$. In 2013-16, women in younger age groups began to report more often the lack of quiet rest at home in comparison with 1988. There were no significant changes in the dynamics of men but their share was higher in comparison with women aged of 25-44 years who are prevented from having rest: $69.8 \%$ and $60.9 \%$, respectively $(p<0.01)$. In $2016-17$, the proportion of women dissatisfied with domestic rest continued to increase in all age groups. Among men, this growth was more evident in the $45-54$ age group - $91.5 \%$. This affected the increase in the number of men and women with "lack of quiet rest" in the general population of $35-64$ years: $82.1 \%$ and $74.5 \%$, respectively $(\mathrm{p}<0.01)$.

Table 3. Gender differences in trends of family stress indicators in population of 25-64 years depending on age

\begin{tabular}{|c|c|c|c|c|c|c|c|c|c|c|c|c|c|c|c|c|c|c|c|c|c|}
\hline & & \multicolumn{4}{|c|}{$25-34$ years } & \multicolumn{4}{|c|}{$35-44$ years } & \multicolumn{4}{|c|}{$45-54$ years } & \multicolumn{4}{|c|}{ 55-64 years } & \multicolumn{4}{|c|}{ 25-64 years } \\
\hline & & \multicolumn{2}{|l|}{$\mathbf{M}$} & \multicolumn{2}{|l|}{$\mathbf{F}$} & \multicolumn{2}{|l|}{ M } & \multicolumn{2}{|l|}{$\mathbf{F}$} & \multicolumn{2}{|l|}{$\mathbf{M}$} & \multicolumn{2}{|l|}{$\mathbf{F}$} & \multicolumn{2}{|l|}{$\mathbf{M}$} & \multicolumn{2}{|l|}{$\mathbf{F}$} & \multicolumn{2}{|l|}{$\mathbf{M}$} & \multicolumn{2}{|l|}{$\mathbf{F}$} \\
\hline & & $\mathbf{N}$ & $\%$ & $\mathbf{N}$ & $\%$ & $\mathbf{N}$ & $\%$ & $\mathbf{N}$ & $\%$ & $\mathbf{N}$ & $\%$ & $\mathbf{N}$ & $\%$ & $\mathbf{N}$ & $\%$ & $\mathbf{N}$ & $\%$ & $\mathbf{N}$ & $\%$ & $\mathbf{N}$ & $\%$ \\
\hline \multicolumn{22}{|c|}{ Have you had any serious family conflicts in the past 12 months? } \\
\hline No & \multirow[t]{6}{*}{1988} & 134 & 66.3 & 93 & 51.4 & 135 & 68.9 & 116 & 56.0 & 126 & 74.1 & 113 & 63.1 & 116 & 76.3 & 90 & 67.7 & 517 & 71.2 & 417 & 58.8 \\
\hline One & & 30 & 14.9 & 24 & 13.3 & 28 & 14.3 & 23 & 11.1 & 11 & 6.5 & 16 & 8.9 & 10 & 6.6 & 10 & 7.5 & 79 & 10.9 & 73 & 10.3 \\
\hline Several & & 29 & 14.4 & 34 & 18.8 & 24 & 12.2 & 33 & 15.9 & 24 & 14.1 & 31 & 17.3 & 19 & 12.5 & 17 & 12.8 & 96 & 13.2 & 118 & 16.6 \\
\hline Often & & 9 & 4.5 & 30 & 16.6 & 9 & 4.6 & 35 & 16.9 & 9 & 5.3 & 19 & 10.6 & 7 & 4.8 & 16 & 12.0 & 34 & 4.7 & 101 & 14.2 \\
\hline Total & & 202 & 100 & 181 & 100 & 196 & 100 & 207 & 100 & 170 & 100 & 179 & 100 & 152 & 100 & 133 & 100 & 726 & 100 & 709 & 100 \\
\hline & & \multicolumn{4}{|c|}{$\chi^{2}=18.681 \mathrm{df}=3 \mathrm{p}<0.001$} & \multicolumn{4}{|c|}{$\chi 2=18.427 \mathrm{df}=3 \mathrm{p}<0.001$} & \multicolumn{4}{|l|}{ n.s. } & \multicolumn{4}{|l|}{ n.s. } & \multicolumn{4}{|c|}{$\chi^{2}=46.262 \mathrm{df}=3 \mathrm{p}<0.001$} \\
\hline No & \multirow[t]{6}{*}{2003} & & & & & & & & & 180 & 59.2 & 268 & 48.4 & 157 & 57.7 & 252 & 48.5 & 337 & 58.5 & 520 & 48.4 \\
\hline One & & & & & & & & & & 57 & 18.8 & 118 & 21.3 & 72 & 26.5 & 158 & 30.4 & 129 & 22.4 & 276 & 25.7 \\
\hline Several & & & & & & & & & & 53 & 17.4 & 115 & 20.8 & 32 & 11.8 & 69 & 13.3 & 85 & 14.8 & 184 & 17.1 \\
\hline Often & & & & & & & & & & 14 & 4.6 & 53 & 9.6 & 11 & 4.0 & 41 & 7.9 & 25 & 4.3 & 94 & 8.8 \\
\hline \multirow[t]{2}{*}{ Total } & & & & & & & & & & 304 & 100 & 554 & 100 & 272 & 100 & 520 & 100 & 576 & 100 & 1074 & 100 \\
\hline & & & & & & & & & & $\chi^{2}=1$ & .334 & $f=3 r$ & $<0.01$ & $\chi^{2}=8$. & $236 \mathrm{~d}$ & $=3 \mathrm{p}=$ & 0.054 & $\chi^{2}=21$ & .432 & $f=3 p<$ & .001 \\
\hline No & 2013 & 121 & 73.3 & 138 & 64.8 & 174 & 66.4 & 197 & 64.8 & & & & & & & & & 295 & 69.1 & 335 & 61.1 \\
\hline One & & 17 & 10.3 & 32 & 15.0 & 41 & 15.6 & 60 & 15.0 & & & & & & & & & 58 & 13.6 & 92 & 16.8 \\
\hline Several & & 22 & 13.3 & 38 & 17.8 & 33 & 12.6 & 63 & 17.8 & & & & & & & & & 55 & 12.9 & 101 & 18.4 \\
\hline Often & & 5 & 3.0 & 5 & 2.3 & 14 & 5.3 & 15 & 2.3 & & & & & & & & & 19 & 4.4 & 20 & 3.6 \\
\hline Total & & 165 & 100 & 213 & 100 & 262 & 100 & 335 & 100 & & & & & & & & & 427 & 100 & 548 & 100 \\
\hline & & n.s. & & & & n.s. & & & & & & & & & & & & $\chi^{2}=8$. & $958 \mathrm{~d}$ & $=3 p<0$ & \\
\hline No & 2017 & & & & & 46 & 64.8 & 66 & 67.3 & 63 & 76.8 & 100 & 72.5 & 102 & 84.3 & 114 & 74.5 & 211 & 77.0 & 280 & 72.0 \\
\hline One & & & & & & 7 & 9.9 & 17 & 17.3 & 5 & 6.1 & 21 & 15.2 & 6 & 5.0 & 14 & 9.2 & 18 & 6.6 & 52 & 13.4 \\
\hline Several & & & & & & 17 & 23.9 & 14 & 14.3 & 8 & 9.8 & 15 & 10.9 & 10 & 8.3 & 13 & 8.5 & 35 & 12.8 & 42 & 10.8 \\
\hline Often & & & & & & 1 & 1.4 & 1 & 1.0 & 6 & 7.3 & 2 & 1.4 & 3 & 2.5 & 12 & 7.8 & 10 & 3.6 & 15 & 3.9 \\
\hline Total & & & & & & 71 & 100 & 98 & 100 & 82 & 100 & 138 & 100 & 121 & 100 & 153 & 100 & 274 & 100 & 389 & 100 \\
\hline & & & & & & n.s. & & & & $\chi^{2}=8$ & $682 \mathrm{~d}$ & $=3 \mathrm{p}$ & 0.05 & n.s. & & & & $\chi^{2}=8$ & $145 \mathrm{~d}$ & $=3 \mathrm{p}=0$ & 056 \\
\hline
\end{tabular}


Table 4: Gender differences in trends of family stress indicators in population of 25-64 years depending on age

\begin{tabular}{|c|c|c|c|c|c|c|c|c|c|c|c|c|c|c|c|c|c|c|c|c|c|}
\hline & & \multicolumn{4}{|c|}{ 25-34 years } & \multicolumn{4}{|c|}{$35-44$ years } & \multicolumn{4}{|c|}{ 45-54 years } & \multicolumn{4}{|c|}{ 55-64 years } & \multicolumn{4}{|c|}{ 25-64 years } \\
\hline & & \multicolumn{2}{|l|}{$\mathbf{M}$} & \multicolumn{2}{|l|}{$\mathbf{F}$} & \multicolumn{2}{|l|}{ M } & \multicolumn{2}{|l|}{$\mathbf{F}$} & \multicolumn{2}{|l|}{ M } & \multicolumn{2}{|c|}{ F } & \multicolumn{2}{|l|}{$\mathbf{M}$} & \multicolumn{2}{|l|}{ F } & \multicolumn{2}{|l|}{$\mathbf{M}$} & \multicolumn{2}{|l|}{$\mathbf{F}$} \\
\hline & & $\mathbf{N}$ & $\%$ & $\mathbf{N}$ & $\%$ & $\mathbf{N}$ & $\%$ & $\mathbf{N}$ & $\%$ & $\mathbf{N}$ & $\%$ & $\mathbf{N}$ & $\%$ & $\mathbf{N}$ & $\%$ & $\mathbf{N}$ & $\%$ & $\mathbf{N}$ & $\%$ & $\mathbf{N}$ & $\%$ \\
\hline \multicolumn{22}{|c|}{ Do you interfere something to have a rest at dwelling? } \\
\hline Yes & \multirow[t]{4}{*}{1988} & 138 & 68 & 82 & 45.1 & 136 & 68.7 & 113 & 54.9 & 120 & 70.2 & 115 & 63.5 & 127 & 83.6 & 92 & 68.7 & 525 & 71.9 & 406 & 57.0 \\
\hline No & & 65 & 32 & 100 & 54.9 & 62 & 31.3 & 93 & 45.1 & 51 & 29.8 & 66 & 36.5 & 25 & 16.4 & 42 & 31.3 & 205 & 28.1 & 306 & 43.0 \\
\hline Total & & 203 & 100 & 182 & 100 & 198 & 100 & 206 & 100 & 171 & 100 & 181 & 100 & 152 & 100 & 134 & 100 & 730 & 100 & 712 & 100 \\
\hline & & \multicolumn{4}{|c|}{$\chi^{2}=20.627 \mathrm{df}=1 \mathrm{p}<0.001$} & \multicolumn{4}{|c|}{$\chi^{2}=7.595 \mathrm{df}=1 \mathrm{p}<0.01$} & \multicolumn{4}{|l|}{ n.s. } & \multicolumn{4}{|c|}{$\chi^{2}=7.998 \mathrm{df}=1 \mathrm{p}<0.01$} & \multicolumn{4}{|c|}{$\chi^{2}=34.306 \mathrm{df}=1 \mathrm{p}<0.001$} \\
\hline Yes & \multirow[t]{4}{*}{2003} & & & & & & & & & 227 & 74.7 & 348 & 62.8 & 204 & 75 & 331 & 63.7 & 431 & 74.8 & 679 & 63.2 \\
\hline No & & & & & & & & & & 77 & 25.3 & 206 & 37.2 & 68 & 25 & 189 & 36.3 & 145 & 25.2 & 395 & 36.8 \\
\hline \multirow[t]{2}{*}{ Total } & & & & & & & & & & 304 & 100 & 554 & 100 & 272 & 100 & 520 & 100 & 576 & 100 & 1074 & 100 \\
\hline & & & & & & & & & & \multicolumn{4}{|c|}{$\chi^{2}=11.950 \mathrm{df}=1 \mathrm{p}<0.001$} & \multicolumn{4}{|c|}{$\chi^{2}=9.977 \mathrm{df}=1 \mathrm{p}<0.01$} & \multicolumn{4}{|c|}{$\chi^{2}=22.409 \mathrm{df}=1 \mathrm{p}<0.001$} \\
\hline Yes & \multirow[t]{4}{*}{2013} & 105 & 63.6 & 121 & 56.8 & 193 & 73.7 & 213 & 63.6 & & & & & & & & & 298 & 69.8 & 334 & 60.9 \\
\hline No & & 60 & 36.4 & 92 & 43.2 & 69 & 26.3 & 122 & 36.4 & & & & & & & & & 129 & 30.2 & 214 & 39.1 \\
\hline Total & & 165 & 100 & 213 & 100 & 262 & 100 & 335 & 100 & & & & & & & & & 427 & 100 & 548 & 100 \\
\hline & & n.s. & & & & $\chi^{2}=6$. & $413 \mathrm{df}$ & $=1 \mathrm{p}<$ & 0.05 & & & & & & & & & $\chi^{2}=7$ & $842 \mathrm{df}$ & $=1 \mathrm{p}<0$ & \\
\hline Yes & 2017 & & & & & 48 & 67.6 & 71 & 72.4 & 75 & 91.5 & 104 & 78.2 & 102 & 84.3 & 109 & 72.7 & 225 & 82.1 & 284 & 74.5 \\
\hline No & & & & & & 23 & 32.4 & 27 & 27.6 & 7 & 8.5 & 29 & 21.8 & 19 & 15.7 & 41 & 27.3 & 49 & 17.9 & 97 & 25.5 \\
\hline Total & & & & & & 71 & 100 & 98 & 100 & 82 & 100 & 133 & 100 & 121 & 100 & 150 & \begin{tabular}{|l|}
100 \\
\end{tabular} & 274 & 100 & 381 & 100 \\
\hline & & & & & & n.s. & & & & $\chi^{2}=5$ & $489 \mathrm{df}$ & $=1 \mathrm{p}<0$ & 0.05 & $\chi^{2}=4$ & $603 \mathrm{df}$ & $=1 \mathrm{p}<$ & 0.05 & $\chi^{2}=0$ & $852 \mathrm{df}$ & $=1 \mathrm{p}<$ & \\
\hline
\end{tabular}

\section{Discussion}

A study of family stress showed that in 1988, men were $7 \%$ more likely than women to report serious illness or death of close relatives over the past year. This proportion was identical among age groups. In 2003-05, the share of those who experienced the loss or serious illness of close relatives significantly decreased in persons of both sexes to $30-40 \%$. At the same time, men became less likely to report such events than women. By 2016-17, the proportion of such persons decreased more evidently down to $20.1 \%$ in men and $28.1 \%$ in women.

Several models of behavior in case of a serious illness or death of close relatives are described in the literature, for example, Parson's theory (1951), as well as the theory of symbolic interactions, analyzing social constructs and aspects of involving family members [9]. The theory of symbolic interactions, according to Blumer et al. (1969) takes into account the capabilities and position of the participants as well as the dynamic of the situation. These theories subsequently received a fundamental assessment (Van der Voort et al., 2009; Rose et al., 2002) in understanding the levels of associated mental states: grief, anger and frustration experienced by family members. The appearance of affective states depended on the ability to accept changes in a sick family member, especially in the context of an ambiguous diagnosis. Caregivers have used different strategies in dealing with these conditions: limiting loss / managing grief; navigating the medical system / increasing the level of ingenuity; questioning the duty of disease management. They also resorted to methods for control and manage the situation and a form of containment (setting limits, ensuring access to treatment, deliberation and motivation). Minimizing losses and rethinking perspectives when confronted with illness involves recognizing their new role as caregivers and incorporating new responsibilities (communicator, teacher, advocate). Gender aspects of psychological stress may not differ but a number of diseases such as cancer are associated with higher levels of distress in women than in men [10]. It was found adverse life events in the family are associated not only with psychological difficulties but also with financial losses, contribute to a career, leisure or education; at the same time, cases of strengthening of family ties and social interaction are described [10].

In an open population of 25-64 years' women more often than men reported changes in marital standing over the past 12 months: married, divorced, left family, widowed, had a child, etc. The frequency of these changes was higher in the younger age group. In 2003-05, the number of reports of changes in marital status increased among women but remained at the same level for men. In 2013-2015, changes in marital standing occurred equally often in men and women, increasing in those aged of 25-34 years up to $28 \%$ (the sum of the answers "one change" and "several changes"). In 2016-17, the number of respondents with changes in marital status during the year decreased significantly. In the group of men aged of 35-44 years this share was $2.8 \%$, and for women it did not exceed $10 \%$ in all age groups.

The difference in the perception of conflicts in the family was found among men and women aged of 25-64 years. In 1988, men more often than women believed that there were no serious conflicts in 
the family, especially in the younger age groups. Attitude toward such events was the same in older age groups in which gender differences was disappearing. In 2003-2005, women were 10\% ahead of men in the frequency of reporting any conflicts in the family. The proportion of women who reported family conflicts declined significantly in 2013-2016 and 2016-17. As for men, conflicts decreased only in the oldest ones aged of 55-64 years. These changes have led to equalization in the frequency of family conflicts in men and women. The absence or presence of stress in relationships objectively affects the well-being and self-rated health [11]. Family stress reduces the effect of social support in women so that married ones have the same risk of coronary heart assault as divorced or single women; but even the reduced effect of social support signifies much less mortality risk from ischemic heart disease in married women [12].

In 1988, the proportion of men for whom "something interferes to have a rest at dwelling" was $23 \%$ higher than women. The proportion of people who cannot rest at dwelling increased with age, reaching $80 \%$. In 2003-2005, their share decreased and in 2013-16 younger women began to more often report the lack of quiet rest at home in comparison with 1988. In 2016-17, the proportion of women dissatisfied with domestic rest continued to increase. This growth was most noticeable in men aged of 45-54 years. This affected the increase in the number of men and women with "lack of quiet rest" in the general population of 35-64 years: $82.1 \%$ and $74.5 \%$, respectively. The lack of rest at dwelling results in sleep disturbances which are important indicators of family stress and self-rated health. Sleep problems act as a mediator between marital status / relationship distress and self-rated health, primarily for married people. The mediating role of sleep disorders differs between divorced men and women [11].

\section{Conclusions}

1. In 1988 , men were $7 \%$ more likely than women to report serious illness or death of close relatives in the past year. By 2016-17, the share of such persons decreased to $20.1 \%$ of men and $28.1 \%$ of women.

2. Women more often than men reported changes in marital status over the past 12 months in 1988: married, divorced, left family, widowed, had a child, etc. The frequency of these changes was higher in the younger age group. In 2013-2015, these changes occurred equally often in men and women but their share decreased subsequently.

3. The difference in the perception of conflicts in the family is present among men and women aged 25-64. In 1988, men more often than women believed that there were no serious conflicts in the family, especially in the younger age groups. Gender gap towards family conflicts is reducing among older people. The proportion of women who reported family conflicts dropped significantly in 2013-2016 and 2016-17. It has led to equalization in the frequency of disagreements in the family among men and women.

4. Majority of population reported that "something interferes to have a rest at dwelling". Men more often than women report "something disturbs their relaxing at dwelling". By 2017, the proportion of such persons increased, reaching $91 \%$ of men and $78.2 \%$ of women aged of $45-54$ years.

\section{References}

1. Tekin A, Karadağ H, Süleymanoğlu M, Tekin M, Kayran $\mathrm{Y}$, et al. (2016) Prevalence and gender differences in symptomatology of posttraumatic stress disorder and depression among Iraqi Yazidis displaced into Turkey. Eur J Psychotraumatol 7: 28556.

2. Kuehner C (2017) Why is depression more common among women than among men? The Lancet Psychiatry 4: 146-158.

3. González G, Vives A (2019) Work Status, Financial Stress, Family Problems, and Gender Differences in the Prevalence of Depression in Chile. Annals of Work Exposures and Health 63: 359-370.

4. Ministerio de salud (2016) Encuesta de Calidad de Vida y Salud [Internet]. Santiago, Chile. Available at http://www. ine.cl/canales/chile_estadistico/calidad_de_vida_y_salud/ calidadvida/folleto-ç- $v$.pdf

5. Ceballos-v PA, Jofré-Aravena V, Mendoza-parra S (2016) Desigualdades en el ejercicio del cuidado a través del enfoque de género. Rev Enfermeriía 1: 47-57.

6. Tunstall-Pedoe H, Kuulasmaa K, Tolonen H, Davidson M, Mendis S (2020) with 64 other contributors for The WHO MONICA Project. MONICA Monograph and Multimedia Sourcebook. World's largest study of heart disease, stroke, risk factors, and population trends 1979-2002. Edited by H. Tunstall-Pedoe. WHO: Geneve; on-line publication. http:// apps.who.int/iris/bitstream/10665/42597/1/9241562234.pdf.

7. UCL department of epidemiology and public health Central and Eastern Europe research group HAPIEE study. Available for: http://www.ucl.ac.uk/easteurope/hapiee-cohort.htm.

8. Gafarov VV, Panov DO, Gromova EA, Gagulin IV, Gafarova AV, et al. (2018) 23-year dynamics (1994-2016) relationships to its health, behavioral characteristics and prevention of cardiovascular diseases among women 25-44 years in Russia /Siberia. Terapevticheskii arkhiv 90: 36-44.

9. Laflamme D, Lévy JJ (2016) Severe illness and death in the family context: the contributions of theoretical models and integrative approaches to the advancement of research. Journals Open Edition. Enfances Familles Générations 24: ePub.

10. Golics CJ, Basra MK, Finlay AY, Salek S (2013) The impact of disease on family members: a critical aspect of medical care. J R Soc Med 106: 399-407.

11. Meadows R, Arber S (2015) Marital Status, Relationship Distress, and Self-Rated Health: What Role for "Sleep Problems"? J Health Soc Behav 56: 341-355.

12. Floud S, Balkwill A, Canoy D (2014) Marital status and ischemic heart disease incidence and mortality in women: a large prospective study. BMC Med 12: 42.
Copyright: (C2021 Valery V Gafarov, et al. This is an open-access article distributed under the terms of the Creative Commons Attribution License, which permits unrestricted use, distribution, and reproduction in any medium, provided the original author and source are credited. 